\title{
Direct access $C T$ for suspicion of brain tumour: an analysis of referral pathways in a population-based patient group
}

K. Zienius ${ }^{1}$, Ip Chak-Lam², J. Park², M. Ozawa ${ }^{3}$, W. Hamilton ${ }^{4}$, D. Weller ${ }^{5}$, D. Summers ${ }^{6}$, L. Porteous ${ }^{7}$, S. Mohiuddin ${ }^{3}$, E. Keeney ${ }^{3}$, W. Hollingworth ${ }^{3}$, Y. Ben-Shlomo ${ }^{3}$, R. Grant ${ }^{8}$ and P. M. Brennan ${ }^{1,8^{*}}$ (D)

\begin{abstract}
Background: Brain tumour patients see their primary care doctor on average three or more times before diagnosis, so there may be an opportunity to identify 'at risk' patients earlier. Suspecting a brain tumour diagnosis is difficult because brain tumour-related symptoms are typically non-specific.

Methods: We explored the predictive value of referral guidelines (Kernick and NICE 2005) for brain imaging where a tumour is suspected, in a population-based patient group referred for direct access $C T$ of the head. A consensus panel reviewed whether non-tumour findings were clinically important or whether further investigation was necessary.

Results: Over a 5-year period, 3257 head scans were performed; 318 scans were excluded according to pre-specified criteria. 53 patients (1.8\%) were reported to have intracranial tumours, of which 42 were significant (diagnostic yield of 1.43\%). There were no false negative CT scans for tumour. With symptom-based referral guidelines primary care doctors can identify patients with a 3\% positive predictive value (PPV). 559 patients had non-tumour findings, 31\% of which were deemed clinically significant. In 34\% of these 559 patients, referral for further imaging and/or specialist assessment from primary care was still thought warranted.

Conclusion: Existing referral guidelines are insufficient to stratify patients adequately based on their symptoms, according to the likelihood that a tumour will be found on brain imaging. Identification of non-tumour findings may be significant for patients and earlier specialist input into interpretation of these images may be beneficial. Improving guidelines to better identify patients at risk of a brain tumour should be a priority, to improve speed of diagnosis, and reduce unnecessary imaging and costs. Future guidelines may incorporate groups of symptoms, clinical signs and tests to improve the predictive value.
\end{abstract}

Keywords: Brain tumor, Brain cancer, Early diagnosis of cancer, Primary health care, General practice, CT scan

\section{Background}

People with a brain tumour see their primary care doctor on average 3 or more times before diagnosis [15], so there may be an opportunity to identify 'at risk' patients earlier. Patients with alarming 'high-risk' symptoms such as focal neurological deficit caused by a brain tumour are usually diagnosed quickly, either through an emergency department or via urgent referral to a

\footnotetext{
*Correspondence: paul.brennan@ed.ac.uk

${ }^{1}$ Translational Neurosurgery, Centre for Clinical Brain Sciences, University of Edinburgh, Edinburgh, UK

${ }^{8}$ Department of Clinical Neurosciences, NHS Lothian, Western General Hospital, Edinburgh, UK

Full list of author information is available at the end of the article
}

specialist clinic (e.g. TIA/stroke clinic). By contrast, patients with more common and lower-risk symptoms (such as headache, cognitive or personality changes, or a combination of these) are most diagnostically challenging and may experience their symptoms for several weeks before specialist referral [21]. The rarity of this diagnosis means possible cases will usually have another less serious cause.

In the UK, only $1 \%$ of adult brain tumours are diagnosed through a "suspicion of cancer" secondary care pathway requiring patients to be seen within 2 weeks of referral [7]. This is one of the lowest of all cancers and is not improving. More adult brain tumours

(c) The Author(s). 2019 Open Access This article is distributed under the terms of the Creative Commons Attribution 4.0 International License (http://creativecommons.org/licenses/by/4.0/), which permits unrestricted use, distribution, and reproduction in any medium, provided you give appropriate credit to the original author(s) and the source, provide a link to the Creative Commons license, and indicate if changes were made. The Creative Commons Public Domain Dedication waiver (http://creativecommons.org/publicdomain/zero/1.0/) applies to the data made available in this article, unless otherwise stated. 
(35\%) are diagnosed through routine secondary care outpatient referral pathways [7]. In all likelihood the symptoms in the majority of these brain tumour patients were insufficient to prompt an urgent cancer referral request.

Guidelines exist to support primary care doctors in identification of patients at risk of having a brain tumour to guide who should be prioritised for urgent brain imaging. Kernick and colleagues' symptom-based guidelines [12] utilise a flag (red/orange/yellow) system that reflects three levels of risk for brain tumour, with emphasis on headache presentations. The National Institute of Health and Care Excellence, (NICE), also developed referral guidelines for adults with suspected CNS cancer. The 2005 [19] guidance was based on groups of symptoms that should precipitate urgent specialist outpatient assessment, typically within 2 weeks. In 2015 [20] the guidelines were simplified to recommend direct access MRI scan within 2 weeks in adults with progressive, subacute loss of central neurological function. The 2015 guideline did not provide guidance for patients with other (e.g. cognition, headache) symptoms.

Our objective was to explore the predictive value of the Kernick and NICE 2005 referral guidelines. To do this we investigated the predictive ability of these current referral guidelines to identify patients with a brain tumour when applied to a population-based patient group referred for direct access CT of the head from primary care. We wanted to determine if there was scope for current referral guidelines to be optimised to improve identification of patients in primary care most likely to have a brain tumour based on their symptoms, in order to expedite urgent brain imaging.

\section{Methods}

The Lothian region of South East Scotland serves a population of 840,000. Since 1999 primary care doctors in Lothian have had direct access to outpatient computed tomography (CT) brain imaging via a single referral pathway, for the exclusion of significant intracranial pathology. This is a group of patients whom the referring primary care doctor did not consider needed urgent brain imaging.

We identified patients aged 16 years or older referred for direct access CT (DACT) between 31 March 2010 and 1 April 2015 from a local electronic database (Fig. 1). All information provided by primary care doctors on the DACT referral was extracted verbatim; the referral is non-structured and there is no minimum dataset. We excluded patients referred for scanning after head trauma to rule out haematoma, those patients with known brain tumour receiving surveillance scans, and where there was no clinical information on the referral form or other electronic sources. All CT head scans were performed in the neuroradiological department at the Department of Clinical Neurosciences, Western General Hospital, Edinburgh, Scotland and reported by a Consultant Neuro-radiologist.

The Kernick referral criteria (Table 1) present 3 symptom groups, where red flag symptoms indicate the probability of an underlying tumour is $\geq 1 \%$, orange flag symptoms that the probability is between 0.1 and $1 \%$, and yellow flag symptoms indicate a probability of less than $0.1 \%$, but above the population rate of $0.01 \%$. The 2005 NICE referral guidelines included details of symptoms that should prompt urgent referral, consideration of urgent referral, or non-urgent referral (Table 2). In these guidelines we anticipated that 'headache of raised intracranial pressure' from the "refer urgently" category may not be associated with an equivalent risk of a brain tumour to 'symptoms related to the CNS' and, therefore, we subdivided these into separate categories (Table 2). This allowed a more accurate comparison of symptom complexes at risk for brain tumour.

Presenting symptoms indicated by the primary care referral were individually recorded and assigned to one of these symptom categories in both the NICE and Kernick referral guidelines independently by a junior doctor and a senior medical student (KZ and $\mathrm{CI}$ ). A Lothian DACT referral is an open text referral through an electronic platform. The referring primary care doctor can write as little or as much information as they feel is necessary. If a symptom appeared in more than one category of the referral guidelines, and the information provided about the presenting symptom was inadequate to assess its severity or characteristics, it was ascribed to the lowest possible category of urgency in the referral guidelines. For example, in the case of 'headache' symptom with no qualifying information, the symptom would be recorded as the non-urgent category in the NICE referral guidelines.

If there was disagreement as to which referral guideline category the presenting symptom should be ascribed to, one of the other authors (PB), a consultant neurosurgeon, made the final judgement. The radiological interval was determined as the time from the date of referral for DACT to the date of brain imaging.

Radiology reports for each patient were categorised by $\mathrm{KZ}$ into one of three groups according to the findings reported by the consultant radiologist: 1) abnormal significant - intracranial tumour 2) abnormal significant - non-tumour and 3) normal/non-significant incidental finding. All scan reports where the imaging was not reported as 'normal' were reviewed by a consultant neurosurgeon, (PB), to assess whether the abnormality identified was likely to be significant in the context of the referral history. This assessment was based on the likely diagnosis (e.g. tumour), the size and location of 
Lothian Primary care doctors have direct access to outpatient CT head scans for the exclusion of significant intracranial pathology

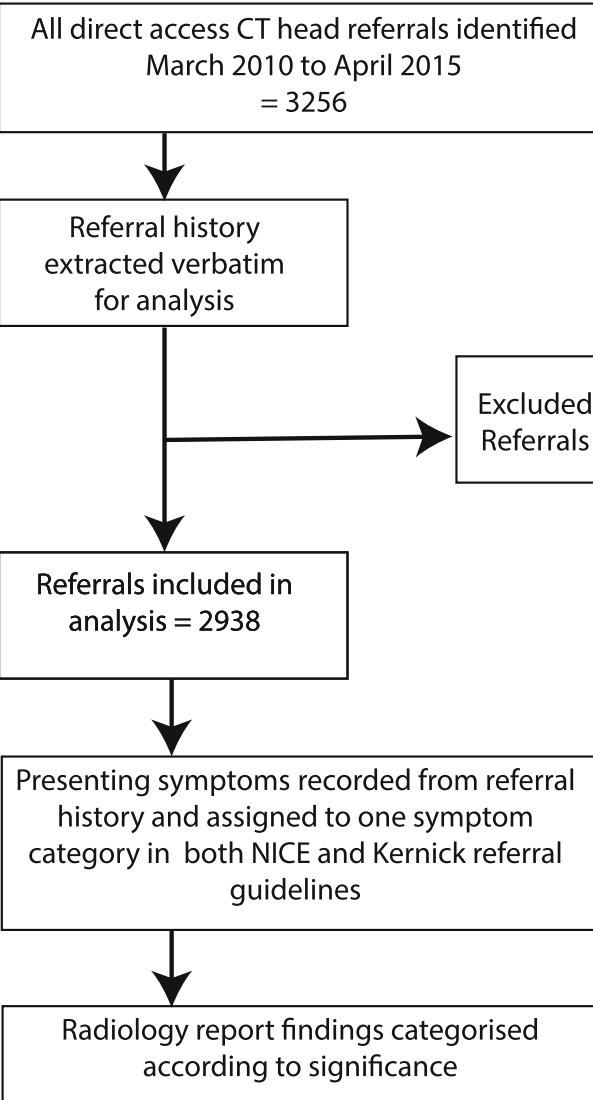

If no tumour identified on index CT scan, subsequent neuro-oncology multi-disciplinary meeting records were reviewed to identify any tumours diagnosed later

Fig. 1 Flow chart of identification and analysis of included referrals

the abnormality, and/or whether the abnormality was thought likely to be responsible for the presenting symptoms, considering any opinion reported by the consultant neuroradiologist. Where necessary, the images were reviewed. Findings were considered 'significant' if clinical details correlated with imaging findings, or if the imaging findings alone were suggestive of requiring further investigations irrespective of the symptoms. Findings were considered 'non-significant' if they were reported as within normal limits for age (e.g. some degree of atrophy or small vessel disease) or were not related to the presenting symptom(s) recorded on the referral.

For all patients where a tumour was not diagnosed on imaging, we determined whether within the duration of the study there was evidence of a tumour diagnosis. We did this by examining all neuro-oncology multidisciplinary meeting (MDM) minutes for the same 5-year timeperiod at Edinburgh Centre for Neuro-Oncology (ECNO), and any subsequent imaging reports on the patient's electronic health record, for a minimum of three years.

Confirmation of CNS tumour diagnosis was based on histopathology for all significant tumours.

We assessed how the imaging report might have influenced the referring primary care doctor. Three practising primary care doctors, (WHa, based in England, LP and DW based in Scotland) reviewed 'abnormal' imaging reports alongside the accompanying 
Table 1 "Kernick's" primary care guidance for imaging patients with suspected brain tumour

Red flag symptoms
- Papilloedema
- significant alterations in consciousness, memory, confusion, or
coordination
- new epileptic seizure
- new onset cluster headache
- headache with a history of cancer elsewhere particularly
breast and lung
- headache with abnormal findings on neurological examination or
other neurological symptoms
Orange flag symptoms
- new headache where a diagnostic pattern has not emerged
after 8 weeks from presentation
- headache aggravated with exertion or Valsalva-like manoeuvre
- headache associated with vomiting
- headache that has been present for some time but have changed
significantly, particularly a rapid increase in frequency
- new headache in patient over 50 years
- headache that wake the patient from sleep
- confusion
Yellow flag symptoms
- diagnosis of migraine or tension-type headache
- weakness or motor loss
- memory loss

referral text and determined a potential action plan for follow-up according to the classification system in Table 3. We examined the management plans according to whether the symptom met the NICE 2005 guidelines for urgent or non-urgent referral.

\section{Statistical methods}

To examine the diagnostic performance of the imaging/ referral guidelines we calculated the diagnostic odds ratios using a logistic regression model for the presence of CNS tumour. Gender and age were considered as confounding variables and were adjusted for in the logistic regression model. Correlation between NICE 2005 and Kernick's referral guideline symptom categories was analysed using the weighted kappa statistic. A frequency table was created of the 'abnormal' findings reported, and of the action plan determined by the primary care doctor. The level of statistical significance was set at $p<0.05$. The data were analysed using Stata/MP 14.2.

\section{Results}

Over a 5-year period, 3256 head scans were performed. After excluding 318 scans according to pre-specified criteria (see Fig. 1 flowchart), 2938 records were reviewed. The mean age was 55.6 years $(\mathrm{SD}=18.56)$ and there were more females $(1748,60 \%)$; Table 4 .

Assessors agreed as to categorisation of the presenting symptom in $97 \%$ of referrals. From 2938 scans, 53 patients $(1.8 \%)$ had intracranial tumours reported, of which 42 were significant (diagnostic yield of 1.43\%). Eleven tumours were thought to be incidental, unrelated to symptom(s) precipitating referral, and likely to be benign meningiomas based on the radiological appearance. None of these patients proceeded to surgery within the time course of the study. No patient without intracranial tumour on the DACT imaging report was subsequently identified to have a tumour on imaging within the study.

Of the significant tumours, $17 / 42(40 \%)$ patients had metastases, 8/42 (19\%) pituitary tumours, 7/42 (17\%) meningiomas, 5/42 (12\%) glioblastoma multiforme (GBM), 4/42 (10\%) non-GBM glioma, and 1/42 (2\%) a CNS lymphoma.

Brain tumours occurred in each of the Kernick categories with the expected frequencies: red flag 3.7\% (expected $>1 \%$ ), orange flag $0.7 \%$ (expected 0.1 to $1 \%$ ) and yellow flag $0.09 \%$ (expected 0.01 to $<0.1 \%$ ) (Table 5 ). Kernick's red-flag group was the only one with a significantly increased risk of brain tumour (OR 5.73, 95\% CI 2.21-14.84) (Table 5). Using the NICE 2005 referral guidelines, 'symptoms related to CNS' had significantly elevated odds ratio for presence of a brain tumour (OR 5.21, 95\% CI 1.81-14.92) compared to the symptoms recommended for non-urgent referral (Table 6).

If the tumours we deemed incidental were instead included in the analysis, the OR for red flag symptoms reduced to $3.86(1.78-8.38)$ and for orange symptoms increased to $1.46(0.56-3.85)$. For the NICE 2005 categories, the odds ratios changed to 3.59 (1.5-8.7), 1.9 (0.63-5.69), and 0.54 (0.13-2.2) for CNS, raised ICP and subacute groups, respectively.

\section{Frequency of non-tumour radiological diagnosis}

Five hundred fifty-nine (19.2\%) scans reported a nontumour finding (Table 7). 177 (31.7\%) of these findings were considered significant based on patient symptoms and radiological opinion. Cerebral atrophy (45.8\%), vascular abnormalities (27.1\%) and sinus disease (13.6\%) were the most common significant findings.

We examined how well the Kernick and NICE 2005 referral guidelines performed at identifying all significant abnormalities, including brain tumours. The odds ratio for red flag symptoms was $0.7(0.5-0.9)$ and for orange symptoms $0.38(0.25-0.58)$. For the NICE 2005 categories, the odds ratios changed to 2.4 (1.5$3.9), 1.57(0.85-2.9)$, and $4.76(2.88-7.87)$ for CNS, raised ICP and subacute groups, respectively. This indicates a worse performance for all categories 
Table 2 NICE 2005 guidelines on specialist referral

\begin{tabular}{|c|c|}
\hline \multirow[t]{15}{*}{ Refer urgently } & Symptoms related to the CNS, including \\
\hline & - progressive neurological deficit \\
\hline & - new-onset/suspected recent onset seizures \\
\hline & - headaches \\
\hline & - mental changes \\
\hline & - cranial nerve palsy \\
\hline & - unilateral sensorineural deafness \\
\hline & in whom a brain tumour is suspected \\
\hline & Headache of recent onset accompanied by features suggestive of raised intracranial pressure, for example: \\
\hline & - vomiting \\
\hline & - drowsiness \\
\hline & - posture-related headache \\
\hline & - pulse-synchronous tinnitus \\
\hline & - or by other focal or non-focal neurological symptoms, for example blackout, change in personality or memory \\
\hline & - a new, qualitatively different, unexplained headache that becomes progressively severe \\
\hline \multirow[t]{4}{*}{ Consider urgent referral } & Patients with rapid progression of: \\
\hline & - sub-acute focal neurological deficit \\
\hline & - unexplained cognitive impairment, behavioural disturbance or slowness, or a combination of these \\
\hline & $\begin{array}{l}\text { - personality changes confirmed by a witness and for which there is no reasonable explanation even in } \\
\text { the absence of other symptoms and signs of a brain tumour }\end{array}$ \\
\hline \multirow[t]{2}{*}{ Consider non-urgent referral } & Patients with: \\
\hline & $\begin{array}{l}\text { - unexplained headaches of recent onset: either present for at least } 1 \text { month, or not accompanied by } \\
\text { features suggestive of raised ICP }\end{array}$ \\
\hline
\end{tabular}

except for subacute symptoms in the NICE referral guidelines, when compared with the performance for identifying only brain tumours.

\section{Management of radiological findings in primary care} We determined possible management of the 559 patients with non-tumour findings in primary care from the available referral history and CT brain imaging findings (Table 8).

$18.6 \%$ of imaging abnormalities were determined to require no further follow-up but did explain the patient's presenting symptom. $38.4 \%$ of radiologically reported

Table 3 Potential action plan suggested by GPs based on direct access head imaging

1 Normal - does NOT explain the presenting symptom(s)

2 Abnormal, but not requiring further investigation - explains the presenting symptom(s) and can be managed in primary care

3 Abnormal, but not requiring further investigation - does NOT explain the presenting complaint, but can be managed in primary care

4 Abnormal, requiring further investigation (such as follow up scans or referral), but NO suspicion of tumour

5 Tumour suspected, requiring referral/follow-up
Table 4 Baseline demographics for patients investigated with direct access CT head imaging over 5 -year period $(N=2938)$

\begin{tabular}{|c|c|c|}
\hline \multirow[t]{2}{*}{ Patient variable } & \multirow[b]{2}{*}{ All } & \multirow{2}{*}{$\begin{array}{l}\text { Significant Brain tumour } \\
\text { Present }(n=42)\end{array}$} \\
\hline & & \\
\hline \multicolumn{3}{|l|}{ Gender } \\
\hline Female, N (\%) & $1748(60)$ & $23(55)$ \\
\hline \multicolumn{3}{|l|}{ Age (years) } \\
\hline Mean, SD & $55.6(18.56)$ & $60.2(14.38)$ \\
\hline \multicolumn{3}{|c|}{ Age group in years, N (\%) } \\
\hline $16-29$ & $335(11.4)$ & $1(2.4)$ \\
\hline $30-39$ & $287(9.8)$ & $1(2.4)$ \\
\hline $40-49$ & $436(14.8)$ & $9(21.4)$ \\
\hline $50-59$ & $547(18.6)$ & $6(14.3)$ \\
\hline $60-69$ & $567(19.3)$ & $15(35.7)$ \\
\hline $70-79$ & $464(15.8)$ & $7(16.6)$ \\
\hline $80+$ & $302(10.3)$ & $3(7.1)$ \\
\hline \multicolumn{3}{|c|}{ Radiological interval (days) } \\
\hline Mean $[95 \% \mathrm{Cl}]$ & $17.3[16.9,17.6]$ & $14.6[12.4,16.7]^{*}$ \\
\hline
\end{tabular}

*statistically significant difference (t-test), $p=0.05$ 
Table 5 Frequency of tumours from direct access CT grouped based on Kernick referral criteria. Odds ratio with 95\% Cl for each flag symptom, for the presence of a brain tumour

\begin{tabular}{|c|c|c|c|c|c|c|c|c|}
\hline & \multirow{3}{*}{ Total } & \multicolumn{4}{|c|}{ Brain tumour } & \multirow[b]{3}{*}{ Odds ratio } & \multirow[b]{3}{*}{$95 \% \mathrm{Cl}$} & \multirow[b]{3}{*}{ PPV } \\
\hline & & \multicolumn{2}{|c|}{ Absent } & \multicolumn{2}{|c|}{ Present } & & & \\
\hline & & Freq & $\%$ & Freq & $\%$ & & & \\
\hline Red flag symptoms & 1141 & 1109 & 92 & 32 & 3.7 & 5.73 & $2.21-14.84$ & 2.8 \\
\hline Orange flag symptoms & 728 & 723 & 99 & 5 & 0.7 & 1.34 & $0.38-4.68$ & 0.7 \\
\hline Yellow flag symptoms & 1069 & 1064 & 99 & 1 & 0.09 & reference & & 0.5 \\
\hline
\end{tabular}

Adjusted for age and sex. An odds ratio of 1.0 indicates the odds of exposure among case-patients are the same as, or similar to, the odds of exposure among controls

abnormalities did not explain the patient's presenting symptoms, but care could be managed in primary care. $34.2 \%$ of patients required referral for further imaging or specialist assessment. $38.7 \%$ of referrals with an imaging abnormality that met the NICE 2005 'non-urgent classification' would still have been referred for further imaging or specialist opinion.

We performed a cross tabulation to compare the three principal categories of NICE and Kernick referral guidelines based on recommended speed of referral (Table 9). Whilst $100 \%$ of Kernick red flag cases were also classified as refer urgently according to the NICE 2005 guidance, there was overall quite a lot of disagreement and the weighted kappa showed only modest agreement beyond chance (0.33). This highlights that the different referral guidelines are making different management recommendations for any given symptom.

\section{Discussion}

\section{Summary}

Our study is the first to examine the diagnostic utility of both the NICE $2005^{19}$ and Kernick [12] guidelines in a population-based patient group and to consider the relevance of significant non-tumour pathology.

The availability of direct primary care access to brain imaging (DACT) varies across the UK. In areas where it is available the Kernick and NICE guidelines may be used to inform referral decisions. Broadly, based on symptoms (red flags or NICE 2005 'symptoms related to the CNS') primary care doctors can identify patients who have a brain tumour with a 3\% PPV. Nearly $80 \%$ of patients whose CT revealed a brain tumour had 'symptoms related to the CNS' on NICE 2005 or Kernick's red-flag symptoms. Overall, the Kernick system performed as predicted [12].

Nineteen percent of scans reported non-tumour findings, $18.6 \%$ of these non-tumour findings were thought by primary care doctors to explain the patient's symptoms. One third of patients with a non-tumour abnormal finding were judged to require onward specialist referral. Access to DACT will influence management of more patients who do not have brain tumours than those that do. Most significant non-tumour findings fall into Kernick's yellow flag group, and into the sub-acute focal deficits of NICE, so DACT should not be restricted to the 'refer urgently' and red-flag symptom categories. Further, whether patients with lower prevalence symptoms (e.g. yellow and orange flags) might also benefit through faster ruling in or out of cancer and the diagnosis of other pathology, and whether this is justified by the cost and potential harm (radiation and over diagnosis) of $\mathrm{CT}$, requires further study.

Whilst existing referral guidelines may meet their intended threshold of specificity, these guidelines are insufficient to adequately stratify patients. Moreover, the different referral guidelines make different management recommendations in terms of urgency for some symptoms. For example, all of the Kernick red flags are also in NICE refer urgently, but $30 \%$ of NICE refer urgently are either in Orange and even a few in Yellow flags.

Table 6 Frequency of referrals for direct access CT grouped based on clinical criteria from NICE 2005 guidelines. Odds ratio with 95\%Cl/PPV for each criteria of NICE 2005 guidelines for the presence of a brain tumour

\begin{tabular}{|c|c|c|c|c|c|c|c|c|}
\hline & \multirow{3}{*}{ Total } & \multicolumn{4}{|c|}{ Brain tumour } & \multirow[b]{3}{*}{ Odds ratio } & \multirow[b]{3}{*}{$95 \% \mathrm{Cl}$} & \multirow[b]{3}{*}{ PPV } \\
\hline & & \multicolumn{2}{|c|}{ Absent } & \multicolumn{2}{|c|}{ Present } & & & \\
\hline & & Freq & $\overline{\%}$ & Freq & $\%$ & & & \\
\hline Symptoms related to the CNS & 1150 & 1117 & 97 & 33 & 3.0 & 5.21 & $1.81-14.92$ & 2.9 \\
\hline Headache \& features of raised ICP & 473 & 469 & 99 & 4 & 1 & 1.65 & $0.41-6.67$ & 0.8 \\
\hline Sub-acute deficits focal/personality/cognitive/behavioural & 525 & 524 & 99 & 1 & $<1$ & 0.31 & $0.03-2.79$ & 0.2 \\
\hline Simple headache & 790 & 786 & 99 & 4 & 1 & reference & & 0.5 \\
\hline
\end{tabular}

Adjusted for age and sex. An odds ratio of 1.0 indicates the odds of exposure among case-patients are the same as, or similar to, the odds of exposure among controls 
Table 7 Frequency of non-tumour findings on direct access CT imaging

\begin{tabular}{lll}
\hline Abnormality & \multicolumn{2}{l}{ Frequency } \\
\cline { 2 - 3 } & Total & Significant (\%) \\
\hline Cerebral atrophy & 206 & $81(39.3)$ \\
Vascular & 195 & $48(24.6)$ \\
Sinus disease & 58 & $24(48.0)$ \\
Arnold Chiari malformation type & 27 & $9(33.3)$ \\
1/tonsillar ectopia & & \\
Benign cystic lesion & 20 & $2(10.0)$ \\
Ventricular abnormality & 11 & $8(72.7)$ \\
ENT tumour & 4 & $1(25.0)$ \\
Other & 38 & $4(10.5)$ \\
Total & 559 & $177(31.1)$ \\
\hline
\end{tabular}

These referral guidelines are recommending quite different decisions for some patients, reflecting the evidence that any individual patient symptom is poorly predictive of a brain tumour [21]. This is important, because inefficient guidelines crowd the referral system, adding to delay in diagnosis for those patients who do have a brain tumour. Whether more liberal DACT criteria is a good use of NHS money requires further research.

\section{Strengths and limitations}

This is the largest reported population-based study of primary care imaging referrals for suspected intracranial abnormality. Grouping was performed by two authors, and a third where necessary, to increase accuracy. All scans were performed at a single clinical neuro-sciences centre and were reported by a consultant neuro-radiologist. As this was part of a retrospective study it allowed sufficient follow-up to record false negatives for a brain tumour with respect to the initial diagnostic CT scan; we did not identify any. A strength is that we examined scan utility in patients with non-tumour pathology, based on a consensus opinion. Despite the large number of referrals that yield of brain tumour cases was not large, hence we have imprecise estimates for our odds ratios.

Many patients with sudden onset symptoms that precipitate immediate hospital assessment at an emergency department will also fall into the Kernick red flag category. Our approach therefore underestimates the predictive ability of the Kernick system in the whole brain tumour population, although our data does reflect the situation in primary care when uncertainty about a brain tumour diagnosis exists.

Table 8 Frequency table action plan by primary care doctor for reported non-tumour findings from direct access head imaging, N (\%)

\begin{tabular}{|c|c|c|c|c|c|}
\hline & $\begin{array}{l}\text { Normal - does } \\
\text { NOT explain } \\
\text { the presenting } \\
\text { symptom(s) }\end{array}$ & $\begin{array}{l}\text { Abnormal, but not requiring } \\
\text { further investigation - explains } \\
\text { the presenting symptom(s) and } \\
\text { can be managed in primary care }\end{array}$ & $\begin{array}{l}\text { Abnormal, but not requiring further } \\
\text { investigation - does NOT explain } \\
\text { the presenting complaint, but can } \\
\text { be managed in primary care }\end{array}$ & $\begin{array}{l}\text { Abnormal, requiring further } \\
\text { investigation (such as follow } \\
\text { up scans or referral), but NO } \\
\text { suspicion of tumour }\end{array}$ & $\begin{array}{l}\text { Tumour } \\
\text { suspected, } \\
\text { requiring } \\
\text { referral/ } \\
\text { follow-up }\end{array}$ \\
\hline $\begin{array}{l}\text { Cerebral } \\
\text { atrophy }\end{array}$ & $12(5.8)$ & $53(25.7)$ & 76 (36.9) & 65 (31.6) & 0 \\
\hline $\begin{array}{l}\text { Ventricular } \\
\text { abnormality }\end{array}$ & $1(9.8)$ & $1(9.8)$ & $5(45.5)$ & $4(36.4)$ & 0 \\
\hline $\begin{array}{l}\text { Benign cystic } \\
\text { lesion }\end{array}$ & 0 & $2(10)$ & $6(30)$ & $12(60)$ & 0 \\
\hline Sinus disease & $7(12.1)$ & $9(15.5)$ & $23(39.7)$ & $19(32.8)$ & 0 \\
\hline $\begin{array}{l}\text { Arnold Chiari } \\
\text { malformation } \\
\text { type 1/ } \\
\text { tonsillar } \\
\text { ectopia }\end{array}$ & $5(18.5)$ & $2(7.4)$ & $12(44.4)$ & $8(29.6)$ & 0 \\
\hline ENT lesion & 0 & 0 & $3(75)$ & $1(25)$ & 0 \\
\hline Vascular & $12(6.2)$ & $37(19)$ & $74(37.9)$ & $72(36.9)$ & 0 \\
\hline Other & $7(18.4)$ & $2(5.3)$ & $15(39.5)$ & $14(36.8)$ & 0 \\
\hline Total & $44(7.7)$ & $106(18.6)$ & $219(38.4)$ & $195(34.2)$ & $6(1.1)$ \\
\hline $\begin{array}{l}\text { NICE } \\
\text { category: } \\
\text { Urgent } \\
\text { referral }(\mathrm{N}, \%)\end{array}$ & $35(6.5)$ & $97(18)$ & $195(36.2)$ & $172(32)$ & $39(7.2)$ \\
\hline $\begin{array}{l}\text { NICE } \\
\text { category: } \\
\text { Non-Urgent } \\
(\mathrm{N}, \%)\end{array}$ & $9(12)$ & $9(12)$ & $24(32)$ & $29(38.7)$ & $4(5.3)$ \\
\hline
\end{tabular}


Table 9 Cross Tabulation of symptoms within Kernick and NICE 2005 referral guidelines based on recommended speed of referral

\begin{tabular}{|c|c|c|c|c|c|c|}
\hline & & & \multicolumn{3}{|c|}{ NICE 2005 categories } & \multirow[b]{2}{*}{ Total } \\
\hline & & & Refer Urgently & Consider urgent referral & Non-urgent referral & \\
\hline \multirow[t]{12}{*}{ Kernick } & \multirow[t]{4}{*}{ Red Flag } & Count & 1141 & 0 & 0 & 1141 \\
\hline & & $\%$ within Kernick & 100.0 & 0.0 & 0.0 & 100.0 \\
\hline & & $\%$ within NICE & 70.3 & 0.0 & 0.0 & 38.8 \\
\hline & & $\%$ of total & 38.8 & 0.0 & 0.0 & 38.8 \\
\hline & \multirow[t]{4}{*}{ Orange Flag } & Count & 468 & 4 & 256 & 728 \\
\hline & & $\%$ within Kernick & 64.3 & 0.5 & 35.2 & 100.0 \\
\hline & & $\%$ within NICE & 28.8 & 0.8 & 32.4 & 24.8 \\
\hline & & $\%$ of total & 15.9 & 0.1 & 8.7 & 24.8 \\
\hline & \multirow[t]{4}{*}{ Yellow Flag } & Count & 14 & 521 & 534 & 1069 \\
\hline & & $\%$ within Kernick & 1.3 & 48.7 & 50.0 & 100.0 \\
\hline & & $\%$ within NICE & 0.9 & 99.2 & 67.6 & 36.4 \\
\hline & & $\%$ of total & 0.5 & 17.7 & 18.2 & 36.4 \\
\hline \multirow[t]{4}{*}{ Total } & & Count & 1623 & 525 & 790 & 2938 \\
\hline & & $\%$ within Kernick & 55.2 & 17.9 & 26.9 & 100.0 \\
\hline & & $\%$ within NICE & 100.0 & 100.0 & 100.0 & 100.0 \\
\hline & & $\%$ of total & 55.2 & 17.9 & 26.9 & 100.0 \\
\hline
\end{tabular}

\section{Implications for practice and research}

The non-specificity of many symptoms associated with brain tumours makes it difficult to identify patients to prioritise for brain imaging. Our data demonstrates that existing guidelines provide some assistance to the primary care doctor. We utilised the 2005 NICE guidelines because they provided a greater granularity of patient symptoms than 2015 guidelines. Since we demonstrated that only 'symptoms related to CNS' is a useful predictor of whether or not a patient may have a brain tumour, the simplification in 2015 may be justified.

A relatively large proportion of our patients were referred for headache only (26.9\%). Certain headache features may raise suspicion of an underlying brain tumour [2], but are still not specific [22]. We previously demonstrated that patients with non-specific symptoms such headache, cognitive changes or personality changes are subjected to the longest delay from onset of symptoms to brain tumour diagnosis [21]. Combining these symptoms may help identify patients to prioritise for brain imaging [21], but this must be balanced against the 'risk' of detecting pathology incidental to the clinical presentation.

In our cohort, there were no false-negative results.

The NICE 2015 guidelines recommend cranial MRI for suspected brain tumour in patients with progressive sub-acute loss of central neurological function (CT only if MRI contra-indicated). The low uptake of imaging for brain tumours in primary care compared to other cancers [6] may in part reflect variation in access to brain imaging. There are fewer MRI scanners in the UK than almost any other Western European country [16]. Our data suggest CT imaging may be adequate as a test in patients deemed at risk of a brain tumour based on headache symptoms. CT is the standard initial imaging modality for patients with acute onset focal stroke-like symptoms [5] and is not diagnostically inferior in identifying clinically significant pathologies for non-acute headache presentation $[8,11]$. Cranial CT costs less and is more readily available than MRI. MRI might be reserved for specific patients, such as those with new onset seizures, where a radiologically subtle low-grade tumour is more likely [26]. Potential risks of ionising radiation are sometimes cited to recommend MRI over CT, although an individual patient's risk is small [24]. It is projected that 1 in 8100 women aged 40 years will develop cancer from a single head CT [24]. The risks may be doubled for 20-year-olds [24] so It may be necessary to prioritise MRI in younger patients.

\section{Comparison with other studies}

Our diagnostic yield of the referral guidelines for a significant brain tumour was $1.43 \%$, slightly higher than that reported by Benamore [3] (for any symptom presentation - 1.28\%) or Simpson [23] (for symptom of headache only $-0.5 \%$ ), both with open access CT.

For some patients a negative scan for a brain tumour provides reassurance $[1,10]$. Incidental findings are not uncommon, even in asymptomatic patients, and can result in additional patient worry, investigations and cost $[3,4,11,18]$. Nearly a fifth of all scans in our study identified a non-tumour finding, similar to patients referred 
for imaging with any symptom [3,17] or headache only [11]. $18.6 \%$ of our non-tumour findings likely explained the symptoms precipitating referral, although the incidence of significant cerebral atrophy may have been overstated, because we performed qualitative estimation of atrophy, which is known to have inter-rater variability [14]. For two thirds of abnormal radiological findings, primary care doctors in our study would be confident to manage patients in primary care, reflecting other reports $[3,11]$. In keeping with previous findings [3], CT for 'simple' headache ("non-urgent" category according to NICE 2005) may require further follow-up or additional investigation in $38.7 \%$ of cases where a non-tumour abnormality is found.

Primary care doctors often report difficulty interpreting neuro-radiological reports, particularly incidental abnormalities [25], and find radiologists' recommendations for further treatment, referral or non-radiological investigation valuable [9]. There is no agreed consensus among radiologists on reporting of incidental findings and/or recommending follow-ups. Primary care doctors rely on their judgement interpreting and relaying these reports to patients, which may cause anxiety for the primary care doctor and lead to additional referrals [13]. A recent qualitative prospective study with $20 \mathrm{GPs}$ identified a need for standardised reporting of scans to improve GP's use of direct-access MRI [25], which may also be appropriate for CT scans.

\section{Conclusions}

Guidelines should provide an evidence-base to assist primary care doctors in identifying patients most at risk of having a brain tumour (i.e. diagnostic accuracy), but also the fastest route to achieve diagnosis (e.g. direct access imaging versus urgent secondary care referral). Direct access CT scanning has a low false negative rate. However, existing referral guidelines are insufficient to adequately stratify patients based on their symptoms according to the likelihood that a tumour will be identified on brain imaging. Improving guidelines to better identify patients at risk of a brain tumour should be a priority, to improve speed of diagnosis, and reduce unnecessary imaging and costs. Future guidelines may need to incorporate groups of symptoms, clinical signs and tests to improve the predictive value. In patients referred for DACT, identification of non-tumour findings may be important for patients. Earlier specialist input into interpretation of these non-tumour abnormality images may be warranted and appreciated.

\section{Abbreviations}

CNS: Central nervous system; CT: Computed tomography; DACT: Direct access CT; MRI: Magnetic resonance imaging; NICE: National institute of clinical excellence

\section{Acknowledgements}

Not applicable.

\section{Authors' contributions}

$P B, R G, Y B, W H a, W H, K Z$, DS conceived and developed the methodology. Data was collected by KZ, PB, JP, IC. Data was anlaysed by KZ, PB, YB, MO, LP, WH, WHa. The analysis and paper was prepared by PB and KZ with input from all the authors. All authors read and approved the final version of the manuscript.

\section{Funding}

This work was supported by a grant from the Brain Tumour Charity, GN000295. The research itself was conducted independently of the Charity, who had no role in the design of the study, or in the collection, analysis or interpretation of the data. They had no role in the writing of the paper

Availability of data and materials

The dataset used during this study are available from the corresponding author in reasonable request.

\section{Ethics approval and consent to participate}

This analysis was undertaken using routinely collected, non-consented data as part of a quality improvement project, approved by the NHS Lothian Quality Improvement Team, comparing the diagnostic pathway for patients referred with a suspected brain tumour by different referral routes. This proposal was reviewed by the South East Scotland Research Ethics service and determined not to require ethical review (ref NR/1610AB14).

Consent for publication

Not applicable.

\section{Competing interests}

The authors declare that they have no competing interests.

\section{Author details}

${ }^{1}$ Translational Neurosurgery, Centre for Clinical Brain Sciences, University of Edinburgh, Edinburgh, UK. ${ }^{2}$ University of Edinburgh Medical School, Edinburgh, UK. ${ }^{3}$ Population Health Sciences, Bristol Medical School, University of Bristol, Bristol, UK. ${ }^{4}$ College of Medicine and Health, University of Exeter, Exeter, UK. ${ }^{5}$ Usher Institute of Population Health Sciences and Informatics, University of Edinburgh, Edinburgh, UK. ${ }^{6}$ Department of Neuroradiology, NHS Lothian, Western General Hospital, Edinburgh, UK. ${ }^{7}$ North Berwick Group Practice, North Berwick, East Lothian, UK. ${ }^{8}$ Department of Clinical Neurosciences, NHS Lothian, Western General Hospital, Edinburgh, UK.

Received: 28 December 2018 Accepted: 31 July 2019

Published online: 20 August 2019

\section{References}

1. Apthorp LA, Daly CA, Morrison ID, Field S. Direct access MRI for general practitioners - influence on patient management. Clin Radiol. 1998.

2. BASH: British Association for the Study of headache. Guidelines for all healthcare professionals in the diagnosis and management of migraine, tension-type headache, cluster headache, medication-overuse headache. 2010.

3. Benamore RE, Wright $D$, Britton I. Is primary care access to $C T$ brain examinations effective? Clin Radiol. 2005.

4. Booth TC, Najim R, Petkova H. Incidental findings discovered during imaging: implications for general practice. Br J Gen Pract. 2016.

5. Broderick J, Connolly S, Feldmann E, Hanley D, Kase C, Krieger D, et al. Guidelines for the management of spontaneous intracerebral hemorrhage in adults: 2007 update. Guideline from the American Heart Association/ American Stroke Association stroke council, high blood pressure research council, and the quality of care and outco. Stroke. p. 2007.

6. England N: Diagnostic imaging dataset: annual statistical release 2015/2016. NHS England 2:2016.

7. England PH. Routes to diagnosis 2006-2016 year breakdown. Public Heal Engl. 2018.

8. Frishberg BM, Rosenberg JH, Matchar DB, McCrory DC, Pietrzak MP, Rozen $T D$, et al. Evidence-based guidelines in the primary care setting: neuroimaging in patients with nonacute headache. Am Acad Neurol [online]; 2000. https://www.aafp.org/afp/2005/0315/p1219.html. 
9. Grieve FM, Plumb AA, Khan SH. Radiology reporting: a general practitioner's perspective. Br J Radiol. 2010.

10. Howard L, Wessely S, Leese M, Page L, McCrone P, Husain K, et al. Are investigations anxiolytic or anxiogenic? A randomised controlled trial of neuroimaging to provide reassurance in chronic daily headache. J Neurol Neurosurg Psychiatry. 2005.

11. Ifediora CO: Insights into radiographic investigations for headaches in general practice. Fam Pract 35:412-419, 2018 Available: http://www.ncbi. nlm.nih.gov/pubmed/29373665. Accessed 23 Dec 2018.

12. Kernick DP, Ahmed F, Bahra A, Dowson A, Elrington G, Fontebasso M, et al. Imaging patients with suspected brain tumour: guidance for primary care. Br J Gen Pract. 2008.

13. Kernick D, Williams S. Should GPs have direct access to neuroradiological investigation when adults present with headache? Br J Gen Pract. 2011.

14. Leonardi M, Ferro S, Agati R, Fiorani L, Righini A, Cristina E, et al.: Interobserver variability in $C T$ assessment of brain atrophy. Neuroradiology 36:17-19, 1994 Available: http://link.springer.com/10.1007/BF00599186. Accessed 23 Dec 2018.

15. Lyratzopoulos G, Neal RD, Barbiere JM, Rubin GP, Abel GA, Schlesinger M: Variation in number of general practitioner consultations before hospital referral for cancer: findings from the 2010 National Cancer Patient Experience Survey in England. Lancet Oncol 13:353-365, 2012 Available: http://www.ncbi.nlm.nih.gov/pubmed/22365494. Accessed 16 June 2017.

16. Martin D: Deadly shortage of cancer scanners that shames UK: Britain has fewer MRI machines than almost any other Western country. Dail Mail: 2014 Available: http://www.dailymail.co.uk/news/article-2672902/Deadly-shortagecancer-scanners-shames-UK-Britain-fewer-MRI-machines-Western-country.html.

17. Mohammad HR, Boardman J, Howell L, Mills RJ, Emsley HCA: Urgent referral for suspected CNS cancer: which clinical features are associated with a positive predictive value of 3\% or more? BMC Neurol 16:152, 2016 Available: http://bmcneurol.biomedcentral.com/articles/10.1186/s12883-016-0677-1. Accessed 23 Dec 2018

18. Morris Z, Whiteley WN, Longstreth WT, Weber F, Lee YC, Tsushima Y, et al. Incidental findings on brain magnetic resonance imaging: systematic review and meta-analysis. BMJ. 2009.

19. NICE: Referral guidelines for suspected cancer. 2005.

20. NICE: suspected cancer: recognition and referral (NG12). 2015 available: https://www.nice.org.uk/guidance/ng12/chapter/1-Recommendationsorganised-by-site-of-cancer\#brain-and-central-nervous-system-cancers.

21. Ozawa M, Brennan PM, Zienius K, Kurian KM, Hollingworth W, Weller D, et al.: Symptoms in primary care with time to diagnosis of brain tumours. Fam Pract 35:551-558, 2018 Available: https:/academic.oup.com/fampra/ article/35/5/551/4840710. Accessed 11 Dec 2018.

22. Schankin CJ, Ferrari U, Reinisch VM, Birnbaum T, Goldbrunner R, Straube A. Characteristics of brain tumour-associated headache. Cephalalgia. 2007.

23. Simpson GC, Forbes K, Teasdale E, Tyagi A, Santosh C. Impact of GP directaccess computerised tomography for the investigation of chronic daily headache. Br J Gen Pract. 2010;60(581):897-901.

24. Smith-Bindman R, Lipson J, Marcus R, Kim KP, Mahesh M, Gould R, et al. Radiation dose associated with common computed tomography examinations and the associated lifetime attributable risk of cancer. Arch Intern Med. 2009;169(22):2078-86.

25. Underwood R, Kilner R, Ridsdale L: Primary care management of headaches and how direct-access MRI fits: a qualitative study of UK general practitioners' views. BMJ Open. 2017;7(11):e018169. https://bmjopen.bmj. com/content/7/11/e018169.

26. Whittle IR. The dilemma of low grade glioma. J Neurol Neurosurg Psychiatry. 2004

\section{Publisher's Note}

Springer Nature remains neutral with regard to jurisdictional claims in published maps and institutional affiliations.

Ready to submit your research? Choose BMC and benefit from:

- fast, convenient online submission

- thorough peer review by experienced researchers in your field

- rapid publication on acceptance

- support for research data, including large and complex data types

- gold Open Access which fosters wider collaboration and increased citations

- maximum visibility for your research: over $100 \mathrm{M}$ website views per year

At BMC, research is always in progress.

Learn more biomedcentral.com/submissions 